\title{
An ankylosaurid dinosaur from Mongolia with in situ armour and keratinous scale impressions
}

Victoria M. Arbour, Nicolai L. Lech-Hernes, Tom E. Guldberg, Jørn H. Hurum, and Philip J. Currie Acta Palaeontologica Polonica 58 (1), 2013: 55-64 doi: http://dx.doi.org/10.4202/app.2011.0081

A Mongolian ankylosaurid specimen identified as Tarchia gigantea is an articulated skeleton including dorsal ribs, the sacrum, a nearly complete caudal series, and in situ osteoderms. The tail is the longest complete tail of any known ankylosaurid. Remarkably, the specimen is also the first Mongolian ankylosaurid that preserves impressions of the keratinous scales overlying the bony osteoderms. This specimen provides new information on the shape, texture, and arrangement of osteoderms. Large flat, keeled osteoderms are found over the pelvis, and osteoderms along the tail include large keeled osteoderms, elongate osteoderms lacking distinct apices, and medium-sized, oval osteoderms. The specimen differs in some respects from other Tarchia gigantea specimens, including the morphology of the neural spines of the tail club handle and several of the largest osteoderms.

Key words: Dinosauria, Ankylosauria, Ankylosauridae, Tarchia, Saichania, Mongolia, Late Cretaceous, Mongolia.

Victoria M. Arbour [arbour@ualberta.ca] and Philip J. Currie [philip.currie@ualberta.ca ], Department of Biological Sciences, CW 405 Biological Sciences Building, University of Alberta, Edmonton, Alberta, Canada, T6G 2E9; Nicolai L. Lech-Hernes [nicolai.lechhernes@bayerngas.com], Bayerngas Norge, Postboks 73, N-0216 Oslo, Norway; Tom E. Guldberg [tguldberg@ miswaco.com ], Fossekleiva 9, N-3075 Berger, Norway; Jørn H. Hurum [j.h.hurum@ @hm.uio.no], Natural History Museum (Geology), University of Oslo, Postboks 1172 Blindern, N-0318 Oslo, Norway.

This is an open-access article distributed under the terms of the Creative Commons Attribution License (for details please see creativecommons.org), which permits unrestricted use, distribution, and reproduction in any medium, provided the original author and source are credited. 
Fof Full text $(951.4 \mathrm{kB})$ 